\title{
Challenges of measuring body temperatures of free-ranging birds and mammals
}

\author{
D. J. McCafferty" ${ }^{1 *}$, S. Gallon ${ }^{1}$ and A. Nord ${ }^{2,3}$
}

\begin{abstract}
The thermal physiology of most birds and mammals is characterised by considerable spatial and temporal variation in body temperature. Body temperature is, therefore, a key parameter in physiological, behavioural and ecological research. Temperature measurements on freely moving or free-ranging animals in the wild are challenging but can be undertaken using a range of techniques. Internal temperature may be sampled using thermometry, surgically implanted loggers or transmitters, gastrointestinal or non-surgically placed devices. Less invasive approaches measure peripheral temperature with subcutaneous passive integrated transponder tags or skin surface-mounted radio transmitters and data loggers, or use infrared thermography to record surface temperature. Choice of technique is determined by focal research question and region of interest that reflects appropriate physiological or behavioural causal mechanisms of temperature change, as well as welfare and logistical considerations. Particularly required are further studies that provide opportunities of continuously sampling from multiple sites from within the body. This will increase our understanding of thermoregulation and temperature variation in different parts of the body and how these temperatures may change in response to physiological, behavioural and environmental parameters. Technological advances that continue to reduce the size and remote sensing capability of temperature recorders will greatly benefit field research.
\end{abstract}

Keywords: Thermometry, Radio-telemetry, Temperature data logger, Passive integrated transponder, Infrared thermography, Thermocouple, Thermoregulation, Heterothermy

\section{Background}

The thermal physiology of vertebrates can be broadly classified by their stability in body temperature and source of body heat [1]. Ectotherms are most commonly poikilothermic where body temperature tracks environmental temperature, allowing thermal tolerances across a wide range of temperatures [2,3]. Endothermy is the maintenance of a high and relatively constant homeothermic body temperature through high metabolic heat production that appears to have evolved separately in avian and mammalian lineages [4]. Core temperature in birds ranges between 34 and $44{ }^{\circ} \mathrm{C}$, scaling with body

\footnotetext{
*Correspondence: dominic.mccafferty@glasgow.ac.uk

${ }^{1}$ Institute of Biodiversity, Animal Health and Comparative Medicine, College of Medical, Veterinary and Life Sciences, University of Glasgow, Graham Kerr Building, Glasgow G12 8QQ, UK

Full list of author information is available at the end of the article
}

size in some groups. Mammalian core temperature varies between $30^{\circ} \mathrm{C}$ in the monotremes and as high as $40^{\circ} \mathrm{C}$ in other groups [5]. However, many species of both mammals and birds are regionally or temporally heterothermic, with variable endothermic heat production and a body temperature that is not regulated within a narrow range $[1,6]$.

Common to all these groups, body temperature is a key physiological parameter that provides important insights into the study of thermoregulation, physiology and behaviour or responses to environmental change [7, 8]. However, while the ectotherm to endotherm continuum is useful for broadly describing the mean physiological state of an organism, this may mask our understanding of the dynamic nature of thermoregulation. The complex control of body temperature in endotherms occurs through autonomic regulation of blood flow in combination with 
a number of processes including shivering and non-shivering thermogenesis, panting or sweating and by a range of thermoregulatory behaviours $[1,9]$. It is a common misassumption that there exists a standard reference core or deep body temperature for each species and each individual [10]. The temperature of any anatomical region is a product of metabolic heat production and blood flow within that region, including the rate of heat lost from physical processes [10]. Confusingly rectal or cloacal temperature is often used synonymously with the terms core or deep body temperature and not surprisingly considerable research effort has been invested in cross-validation of techniques to measure these respective temperatures [11-14]. Therefore, for any study involving body temperature measurement it is important to understand the spatial variation and differential regulation in temperature within the body and how the temperature of different body regions may change with time and environmental context. Here, the term core temperature is used throughout to describe the homeostatic temperature within the centre of the body.

Accordingly, the first step in deciding which technique to use when sampling temperature from an animal is to determine which body region is suited to answer the research question and on what timescale measurements are required. Precision and response time of the sensor should be chosen to reflect the rate of change of temperature at that site. However, choice of measurement sites may be constrained by the extent to which invasive methods are appropriate for the study species.

This review is aimed at researchers wishing to undertake body temperature measurements on freely moving or free-ranging birds and mammals. In particular, the merits of a range of techniques that are suited to studies of animals in the wild are considered (Table 1). This is intended to help researchers choose the most appropriate technologies and complements previous reviews that have focused either on single techniques [15-17] or have examined body temperature measurement in particular taxonomic groups $[10,18,19]$. The current review compares techniques that measure core and peripheral temperature and discusses calibration, analytical approaches and future instrument design.

\section{Internal temperature}

\section{Thermometry}

Rectal or cloacal temperature is commonly measured using thermometry. This fast, affordable, and minimally invasive method relies on inserting a thin temperaturesensitive probe into the rectum via the anus or cloaca [20-22]. It is commonly undertaken using thermocouples or thermistors either custom adapted for use or using standard medical or veterinary thermometers.
Oesophageal temperature may also be taken in this way [23]. Thermometry has wide applicability in ecology, and has been used for example to record functional thermoregulation in relation to climatic variables, immune function, natural occurrence of pathogen infection and when studying the ontogeny of thermoregulation [20, 24-27]. While highly accurate and repeatable [20], thermometry generally only provides a cross-sectional temperature sample, because subjects must be captured and handled during sampling. The stress of capture and indeed the temperature measurement itself can bring about stress-induced hyperthermia $(\mathrm{SIH})$ mediated by the sympathetic adrenal and the hypothalamic-pituitary-adrenal (HPA) axes, as well as through increased metabolic heat production associated with the escape response $[28,29]$. Therefore, the time from capture to measurement should be as rapid as possible, particularly for small animals. For example, measurement of rectal temperature in mice typically results in an increase of $0.5-1.5{ }^{\circ} \mathrm{C}$ in $10-15 \mathrm{~min}$ [23] and is associated with peripheral cooling at the surface through vasoconstriction [30]. Thermometry is, therefore, inappropriate for studying functional body temperature responses or longitudinal patterns in body temperature regulation in free-ranging or free-moving animals. This problem can be partly remedied by physically attaching one or several thermocouples by leads to different body regions to allow for continuous body temperature recordings (Nord and Folkow, unpublished data) or by connecting temperature sensors to an externally mounted radio transmitter [31]. However, physical attachment is a viable option only for inactive, or relatively inactive animals or when contained in a confined space (such as a metabolic chamber or a roosting cavity) where thermocouple wiring can be adjusted to confinement size and animal movement is relatively small. Stress from having the thermocouple attached may also bias the temperature reading (Esa Hohtola, pers. comm., see also [32]). Regardless of such shortcomings, thermometry remains an inexpensive, fast, and attractive method for body temperature recording, especially when cross-sectional data are desirable and subjects can be caught and measured with relative ease. With larger animals, measurements of blood and muscle temperature may be made by percutaneous insertion of a thermistor via a catheter and temperature logged with a surface-mounted recorder [33-35]. This allows for continuous monitoring of body temperature while animals are exhibiting natural behaviours but requires recapture of the animal for removal of instrument.

One indirect thermometry method of estimating rectal temperature is to measure the temperature of newly defecated faeces [36]. This technique has recently been applied to body temperature measurement by careful 


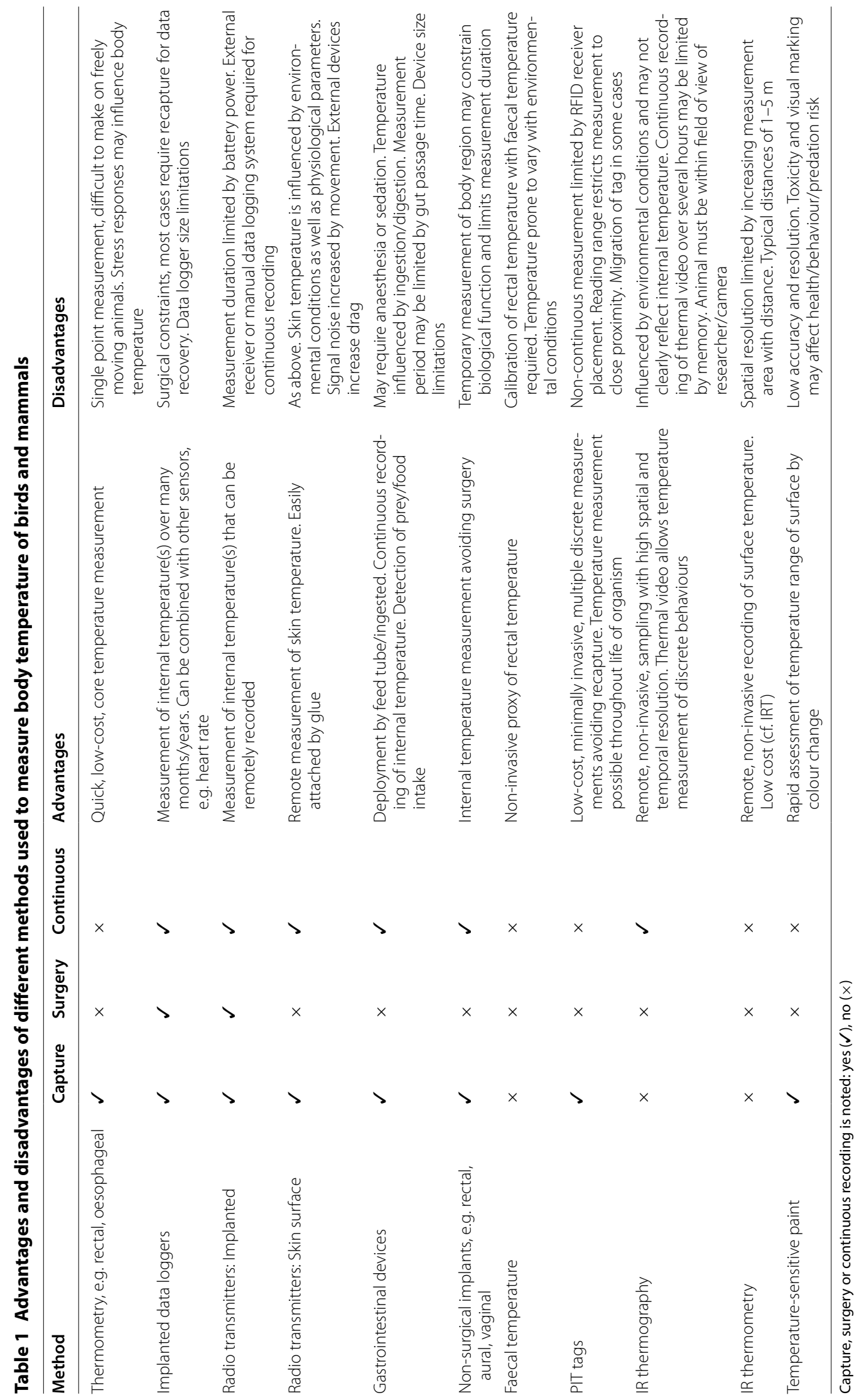


calibration of the rate of temperature change following defecation [37]. However, it is likely to have limited applicability by the fact that it only provides single time point measurement and will be strongly influenced by changes in environmental conditions.

\section{Surgical implants}

Intra-peritoneal (and sometimes also intra-abdominal) implants are commonly used when continuous long-term body temperature profiles are desirable, such as when studying the functional characteristics of thermoregulation. Implantable temperature-sensitive devices have been used for this purpose in a wide range of species (see references in [17]), and have provided considerable insights into the thermal biology of a large number of free-ranging animals. The devices basically come in two forms; data loggers and radio transmitters. Common to all implants is the need for surgery, which requires anaesthesia. Sedation itself is often unproblematic, but mortality may occur despite proper dosage [38] so care must be taken to monitor vital signs and provide post-surgical recovery. Although surgical implantation is logistically demanding, it has been successfully used on wild animals by either transporting animals to temporary surgical facility [39] or directly undertaking surgery in the field [40]. Implantation of devices may actually be preferable to externally attached loggers in long-term studies [41].

\section{Data loggers}

Most data loggers integrate a thermistor, a real-time clock, and an internal memory for storing temperature, time and date at a user-defined interval. Temperature sensors may be held within the body of the logger but where more rapid response rates are required these can be mounted on external leads or on the surface of the instrument [42]. Data loggers are invaluable when recording long-term body temperature profiles and are often combined with heart rate loggers [43-45]. Logger weight considerations can constrain use of many commercially available data loggers on small species. For example, Thermocron iButtons (Dallas Semiconductor, Sunnyvale, CA, USA), which are amongst the smallest available data loggers, weigh approximately $3 \mathrm{~g}$ in their standard format. However, iButtons can be remodelled for a $50 \%$ weight reduction [17] and water proofing [19], which allows for measurements on considerably smaller subjects $(\geq 30 \mathrm{~g})$.

Implanted data loggers are, therefore, particularly suited to long-term deployments. Examples of these include studies on thermoregulation [42, 43], circadian rhythms [39, 46-48], hibernation and torpor [40, 49, 50], temperature change during diving and foraging $[43,51$, 52], incubation [53], egg laying in monotremes [54] and comparison between wild and captive species [47, 55]. One disadvantage with data loggers is that animals must normally be recaptured for data retrieval, which can be difficult or even impossible for some species. Technological solutions have been developed to remedy this, for example using UHF transmission of temperature data to a telemetry collar that can then transmit data by VHF [56] or implanted archive tags on pinnipeds that float to the sea surface and transmit data by satellite when the animal dies [57].

\section{Radio transmitters}

Animals implanted with radio temperature transmitters do not require recapture as data are transmitted continuously, and in general the small size does not impose weight constraints. However, the applicability of radio transmitters can be constrained by battery life and signal strength is sometimes compromised in structurally complex habitats. In addition, transmitters do not have internal storage capacity, which requires manual recording of signal pulse rate or the purchase of automated recording equipment [58]. Care must, therefore, be taken when tracking animals to ensure that disturbance does not disrupt natural behaviours. Automated recording systems provide a solution to this problem, allowing recording of multiple individuals where good signal transmission is possible but will obviously be constrained by range size and habitat complexity for some species. Regardless of such potential shortcomings, radio transmitters continue to provide an effective option for remote recording of body temperature in free-ranging animals over relatively long time periods [50, 59-62].

\section{Gastrointestinal devices}

Ingestion of radio-telemetry pills or miniaturised data loggers allows a relatively non-invasive method of measuring internal temperature. These devices record temperature during passage through the gastrointestinal tract and have been used widely on relatively large species and in humans $[10,63,64]$. Recording duration is determined by gut passage rate, which may vary from hours to weeks but in large ruminants devices have been retained for up to 4 years (retention time was actually improved by increasing the size of the device) [56]. The extent to which gastrointestinal temperature reflects core temperature is dependent on food ingestion and subsequent digestion (and fermentation in the case of ruminants). The temperature recorded may be filtered to account for these processes and thereby provide informative longer term recording of core temperature [56]. Radio-telemetry pills have the advantage that temperature can be recorded externally and do not require recovery of the pill. Systems that provide a combination of radio-telemetry and data 
logger output have been custom built for this purpose $[56,64]$. By far the greatest application of gastrointestinal sensors in wild species has been to detect feeding events in marine endotherms, to which these devices are especially appropriate as the stomach temperature of these animals drops temporarily during the ingestion of cooler ectothermic prey [65-67]. The location of the temperature sensor in the stomach will affect the likelihood that ingested prey comes into contact with the sensor $[65,68]$. Thermistor pills can either be gently pushed through the oesophagus via a flexible silicone intubation tube under anaesthesia or fed to the studied animal inside a refrigerated prey during captive experiments. Recorded temperature measurements are stored in the device and retrieved through stomach flushing at the end of experimentation, e.g. after about 10 days for captive seabirds [69]. Measured stomach temperatures of free-ranging species are transmitted to an external logger placed on the back of the animals that is subsequently retrieved. More recently signals from temperature sensors are monitored by satellite transmitters and data are directly relayed through the Argos Data Collection and Location System [70]. Stomach temperature sensors have also been used in conjunction with other temperature loggers to examine physiological processes such as hypothermia [71] and the heat increment of feeding [72]. More recently, stomach temperature sensors have been identified as a promising method to study the suckling behaviour and the transition to nutritional independence of pinnipeds $[73,74]$.

\section{Non-surgical methods for measurement of internal temperature}

In cases where surgical implantation of temperature sensors may not be possible some novel methods of have been used to obtain internal body temperatures. For example, these include temporarily inserted rectal [75], vaginal [76] or aural temperature [77] data loggers. These techniques may be suited to relatively short time periods (days-weeks) and are especially useful for large species where subjects can be recaptured.

\section{Peripheral temperature}

Temperature at the periphery, either below (subcutaneous) or at the skin surface is controlled by peripheral blood circulation and body insulation, and is also affected by environmental factors such as ambient temperature and wind speed. For small animals (where body size typically is not sufficiently large to maintain a regulated core-to-shell temperature gradient), changes in skin surface temperature may be closely correlated with internal temperature $[18,58,78,79]$ but with increasing body size peripheral temperature is generally not a reliable predictor of core temperature $[80,81]$. These factors will be important to consider when evaluating the suitability of peripheral temperature measurement for any given project/research question.

\section{Passive integrated transponder (PIT) tags}

In situations where surgery is not practical, it is possible to implant subjects subcutaneously with small temperature-sensitive transponders. These self-contained devices provide both a unique identification number and temperature data [82]. Devices were developed for veterinary applications but have since been used to study body temperature profiles in wild birds [79] and mammals [18]. At least in birds, implantation is minimally disturbing and does not cause bleeding or subsequent inflammation. Thus, it is not necessary to apply anaesthesia and analgesia and recovery time can be kept short. In addition, because these devices are both small (approximately $12 \times 2 \mathrm{~mm}$ ) and lightweight $(<0.1 \mathrm{~g})$ they can be implanted into small animals (body mass $\geq 2$ g). Being contained within a glass container they are also biologically inert, and will remain active throughout the life of the animal. Migration of the tag may be reduced by choosing PIT tags that have an antimigration cap. However, unlike transmitters or data loggers, the implantable transponders do not transmit or store data, but must be within the electromagnetic field of a receiving unit for data to be collected. This poses two problems: firstly, the need for sufficient field strength constrains the maximum distance between the subject and the receiving unit to about $0.3 \mathrm{~m}$. Secondly, because of interference, data collection will become arbitrary if more than one transponder is contained within the same electromagnetic field at any given time. For these reasons, the use of implantable transponders may be more appropriate in captive settings or in field situations were subjects could be contained within the field of the receiving unit (e.g. roosting animals) or can be attracted to the receiver by others means (e.g. receiving unit set up at nests or feeding stations [19]), and in those cases where only one animal's temperature is of interest. Although PIT tags are generally inserted subcutaneously to record temperature it would be possible to implant them deeper within the body, but of course detection distance would limit the implant location and so may not be suitable for larger species. Care must also be taken to interpret temperature data from PIT tags implanted into different body regions. For example, PIT tags inserted subcutaneously or in semimembranous muscle in goats differed by up to $3.5^{\circ} \mathrm{C}$, while a PIT tag inserted into the retroperitoneum was only $0.2{ }^{\circ} \mathrm{C}$ less than temperature recorded by a digital rectal thermometer and an intra-abdominal data logger [14]. 


\section{Skin temperature measurement}

A commonly used and moderately non-invasive method for temperature sampling involves fitting subjects with an externally attached radio transmitter [83]. Having captured the animal, it is often necessary to trim or remove part of the plumage or fur (normally on the lower back) for the transmitter to be attached in close proximity to the skin. Because only a relatively small area of integument is removed, remaining feathers or fur can effectively cover the attachment site. Thermal images of birds instrumented in this way reveal no obvious differences in surface temperature and, therefore, attachment seems to have little (if any) influence on insulation (McCafferty \& Nord, unpublished data; see also [84]). Other methods of measuring skin temperature include using data loggers mounted to radio collars $[49,85]$ or glued securely with epoxy to the integument to track temperature over several days [86].

Provided that transmitters are in proper contact with the skin, they will provide reliable, high-resolution data on skin temperature fluctuations [58, 87]. Data can also be received over long distances $(1000+\mathrm{m})$. Variation in the proximity of attachment to the skin, which is likely when the pelage or plumage is trimmed rather than removed, will introduce between-subject variation in transmitted temperature and skin temperature will always be influenced to some extent by environmental conditions (Lehmann et al. in review). One additional constraint of externally mounted instruments is the effect of the device on the animal. The recommended size of instruments is $1-5 \%$ of body mass for birds or bats, and $10 \%$ for non-flying animals [88, 89], although it is advisable to assess the full impact of device on drag and energy expenditure [90].

\section{Infrared thermography}

When subjects cannot or need not be captured, there are possibilities to study body temperature patterns using infrared thermography (IRT). IRT involves the detection of infrared radiation, which is emitted from all surfaces with a temperature above $0 \mathrm{~K}$ [16]. An obvious strength of IRT as compared to other means of temperature sampling is that it allows for an integrated measure of the thermal properties of different surfaces of the body in freely moving animals and functional variation in heat loss from the surface of different body regions [91, 92]. In endotherms with a relatively thin pelage or plumage, thermal imaging could also be optimised to investigate regional heterothermy. This would allow assessment of the extent to which animals strategically alter blood flow to the body periphery to control heat loss. However, IRT only determines surface temperature and, therefore, changes in internal temperature must be measured using other techniques (e.g. [93]). Attempts have been made to correlate IRT surface temperature measurements with core body temperature. For example, by removing a small area of plumage from the head of ducklings, scalp temperature was shown to be within $1{ }^{\circ} \mathrm{C}$ of cloacal measurements over a range of ambient temperatures [94]. Similarly, facial skin temperature measured via thermal imaging explained more than $80 \%$ of the variation in core body temperature in domestic fowl [95]. Due to the lack of insulation around the eye, the temperature of this region is often closest to core temperature compared to other peripheral regions. The surface temperature of the eye region is not a reliable predictor of core temperature [96]. However, measurement of temperature of the eye region or other bare skin areas may be useful for detecting stress responses $[97,98]$.

\section{Alternatives to infrared thermography for remote, non-contact sampling}

Although recent technological advancements have made thermal imaging cameras more affordable, infrared thermometers provide the opportunity to obtain non-invasive measurements of surface temperature at a fraction of the cost. These devices are most accurate when animals can be approached within a few metres and mean (min and max) temperature can be recorded from a given area highlighted by a laser guide [99]. With increasing distance the measurement 'spot' becomes too large for measuring the temperature of specific regions. Nevertheless, these devices gave equally good measurements of skin temperature in ectotherms as did thermistors placed on the skin [100], but of course peripheral temperature recorded with this technique will differ from cloacal temperature [101]. Infrared sensors can provide continuous monitoring of surface body temperature with an automated data collection system or can also be used remotely in nest boxes to study thermoregulation and torpor [102]. Surface temperature has been recorded using temperaturesensitive paint but accuracy is relatively poor $\left(\right.$ ca. $1{ }^{\circ} \mathrm{C}$ ) and requires careful colour calibration [94]. Toxicity and influence of colour marking on behaviour or predation risk also need to be considered.

\section{Calibration and data analysis}

An essential requirement of all body temperature measurement is to calibrate instruments against known standards (i.e. mercury thermometer or platinum resistance thermometer). This can be undertaken in water baths (in the laboratory) or thermos flasks (in the field) or in air in temperature chambers, and is a crucial step to improve the accuracy of temperature data [103]. It is also essential to account for inter-instrument variation whenever multiple instruments are used on a single animal, single 
instruments are used on many individuals or where many identical temperature-sensing setups are deployed in the same experiment [104]. The importance of calibration drift over time is an important consideration for implanted logging systems and externally mounted radio transmitters [105]. Where possible, it is, therefore, prudent to check calibration before and after deployment to account for this. For infrared thermography, calibration can be checked against a blackbody of known emissivity that is monitored by a thermocouple/data logger before and after the measurement session or continuously in the field of view [77].

An essential consideration when interpreting peripheral temperature data relates to the temporal and functional variation in internal-external temperature covariance, especially in large animals $[81,106]$. The relationship between internal and peripheral temperature is not always the same in active and inactive animals. For example, when studying the body temperature response to a simulated pathogen infection in birds, there was a strong linear relationship between implanted and externally attached transmitters during the night (when birds were roosting), whereas skin temperature varied independently of core temperature during the day (when active and subjected to variation in ambient temperature and exposure to shade/sun) [58]. However, skin temperature was a good predictor of cloacal temperature throughout the daily cycle in a different bird species [107]. Care must be taken to investigate the nature of the relationship between core and peripheral temperatures and understand how temperature of different body regions varies with both temporal (day/night, active/passive) and state-dependent (age, sex, size, etc.) factors. Studies relying on remote sensing techniques should, therefore, take proper care to carefully calibrate sampling methods against other regions of the body to assess the extent to which peripheral temperature reflects internal and external temperature. One useful approach that may aid choice of the most reliable/consistent indicator of internal temperature has been to apply multivariate statistical techniques such as principle component analysis to multiple peripheral measurements [108].

Continuous sampling of body temperature is often considered advantageous as it avoids errors associated with non-random point sampling of temperature [109]. As a consequence researchers are faced with the analysis of high-resolution data over long time periods. Certain data (e.g. those collected by externally mounted radio-telemetry system) may also require filtering due to sampling artefacts associated with movement of animals and/or signal noise [58]. Customised filtering programs are, therefore, supplied as part of proprietary software or require development of appropriate algorithms. Similarly thermal imaging requires considerable post-collection extraction of temperature from still or thermal video using image analysis software. One of the greatest difficulties involved is tracking regions of interest as animals move. Researchers should thus not underestimate the time taken for image processing to extract temperature data from complex shapes of animals. Some attempts have been made to use pattern detection algorithms in humans [110] but as yet, automated systems for complex shape recognition are not widely used in animal studies, with the exception of counting animals from heat signatures [111].

For all methods that generate continuous data, it is advised that researchers consider sampling interval prior to the start of data collection, to set the interval between successive data points such that it corresponds to the rate of change expected in any parameter that is investigated (e.g. short sampling interval in studies of thermoregulatory mechanisms; longer sampling interval for core temperature in hibernating animals). Prudency with regard to sampling interval will also maximise logger performance, such that internal memory (where applicable) is not exhausted after an insufficiently long measurement period.

\section{Conclusions and future directions}

Measuring internal body temperature in freely moving animals is especially challenging due to the need to implant data loggers or radio transmitters. Where this is not possible for logistical or welfare concerns, less invasive techniques involving measurement of subcutaneous or peripheral temperature, or thermal imaging are widely available (Table 1). Researchers should, therefore, consider carefully if it is the all important 'core' temperature that is needed to answer research questions or if peripheral temperature may be either a suitable proxy or even a more informative measure for the particular questions of interest. For example, in many physiological studies multiple measurements from different regions are likely to be necessary to obtain a sufficiently detailed view of thermoregulatory processes, while in ecological/ behavioural studies one appropriately chosen single temperature measurement may suffice. To this end, sampling interval should also be adjusted such that it provides the necessary temporal resolution in situation where study design may risk exhausting device memory. Particularly required are the development of appropriate methods for sampling from multiple sites from within the body, which will increase our understanding of how temperature varies in different regions/organs and how these change in response to physiological, behavioural and environmental parameters. Acoustic temperature telemetry that is currently used to measure temperature in fish and aquatic 
reptiles [112] could also be useful for remote temperature sensing of diving birds and mammals. Future applications will be aided by technological advances that continue to reduce the size and data gathering capabilities of temperature-sensing methods. In particular, the development of medical sensing systems linked to mobile phone and wifi communication [113] provides considerable potential for remote sensing of body temperature in wild animals.

\section{Authors' contributions}

DM, SG and AN jointly organised workshop that provided conceptual basis for review and all undertook writing and editing of the manuscript. All authors read and approved the final manuscript.

\section{Author details}

${ }^{1}$ Institute of Biodiversity, Animal Health and Comparative Medicine, College of Medical, Veterinary and Life Sciences, University of Glasgow, Graham Kerr Building, Glasgow G12 8QQ, UK. ${ }^{2}$ Department of Arctic and Marine Biology, Arctic Animal Physiology, Arktisk biologibygget, University of Troms $\varnothing$, 9037 Tromsø, Norway. ${ }^{3}$ Section for Evolutionary Ecology, Department of Biology, Lund University, Ecology Building, 22362 Lund, Sweden.

\section{Acknowledgements}

This review was the outcome of WS1 Body temperature measurement in freeranging animals on 24 September 2014 at The 5th Bio-logging Science Symposium (BLS5), Strasbourg, France. The workshop was supported and funded by IBAHCM, University of Glasgow. We thank speakers A. Gleiss, B. Cresswell, E. Hohtola, K. Herborn, N. Weissenböck, P. Jerem, P. Ponganis, P-Y. Henry and $S$. Annaheim and all participants for very useful discussion of techniques. R. Dwyer kindly provided insights into acoustic temperature measurement. DM was supported in this work by a grant from the Carnegie Trust for the Universities of Scotland. AN was funded by the Royal Physiographic Society in Lund and the Swedish Research Council (Grant No. 637-2013-7442).

\section{Competing interests}

The authors declare that they have no competing interests.

Received: 20 January 2015 Accepted: 11 September 2015 Published online: 30 September 2015

\section{References}

1. Randall D, Burggren W, French K. Eckert animal physiology: mechanisms and adaptations. Eckert animal physiology: mechanisms and adaptations, vol. 4. 1997.

2. Hoffmann AA, Chown SL, Clusella-Trullas S. Upper thermal limits in terrestrial ectotherms: how constrained are they? Funct Ecol. 2013;27(4):934-49. doi:10.1111/j.1365-2435.2012.02036.x.

3. Duman JG. An early classic study of freeze avoidance in marine fish. J Exp Biol. 2014;217(6):820-3. doi:10.1242/jeb.092239.

4. Clarke A, Portner H-O. Temperature, metabolic power and the evolution of endothermy. Biol Rev. 2010;85(4):703-27. doi:10.1111/j.1469-185X.2010.00122.x.

5. Clarke A, Rothery P. Scaling of body temperature in mammals and birds. Funct Ecol. 2008;22(1):58-67. doi:10.1111/j.1365-2435.2007.01341.x.

6. Barnes BM. Freeze avoidance in a mammal-body temperatures below 0 degrees $C$ in an arctic hibernator. Science. 1989;244(4912):1593-5. doi:10.1126/science.2740905.

7. Khaliq I, Hof C, Prinzinger R, Boehning-Gaese K, Pfenninger M. Global variation in thermal tolerances and vulnerability of endotherms to climate change. Proc R Soc B Biol Sci. 2014;281(1789). doi:10.1098/ rspb.2014.1097.

8. Sunday JM, Bates AE, Dulvy NK. Global analysis of thermal tolerance and latitude in ectotherms. Proc R Soc B Biol Sci. 2011;278(1713):1823-30. doi:10.1098/rspb.2010.1295.
9. Yahav S. Regulation of body temperature: strategies and mechanisms, chapter 37. In: Scanes CG, editor. Sturkie's avian physiology. 6th ed. San Diego: Academic Press; 2015. p. 869-905.

10. Taylor NAS, Tipton MJ, Kenny GP. Considerations for the measurement of core, skin and mean body temperatures. J Therm Biol. 2014;46:72101. doi:10.1016/j.jtherbio.2014.10.006.

11. Misson BH. Note on measurement of body-temperature in Gallus domesticus. J Therm Biol. 1978;3(3):175-6. doi:10.1016/0306-4565(78)90015-3.

12. Green AR, Gates SG, Lawrence LM. Measurement of horse core body temperature. J Therm Biol. 2005;30(5):370-7. doi:10.1016/j. jtherbio.2005.03.003.

13. Ozeki LM, Fahlman A, Stenhouse G, Arnemo JM, Caulkett N. Evaluation of the accuracy of different methods of monitoring body temperature in anesthetized brown bears (Ursus arctos). J Zoo Wildl Med. 2014;45(4):819-24. doi:10.1638/2014-0039.1.

14. Torrao NA, Hetem RS, Meyer LCR, Fick LG. Assessment of the use of temperature-sensitive microchips to determine core body temperature in goats. Vet Record. 2011;168(12):328-45. doi:10.1136/vr.c6200.

15. Special issue on. The contribution of radiotelemetry to the advancement of thermoregulatory research. J Therm Biol. 2012;37(4):249. doi:10.1016/j.jtherbio.2012.03.001.

16. McCafferty DJ. Applications of thermal imaging in avian science. Ibis. 2013;155(1):4-15. doi:10.1111/ibi.12010.

17. Lovegrove BG. Modification and miniaturization of Thermochron iButtons for surgical implantation into small animals. J Comp Physiol B Biochem Syst Environ Physiol. 2009;179(4):451-8. doi:10.1007/ s00360-008-0329-X.

18. Wacker CB, Daniella Rojas A, Geiser F. The use of small subcutaneous transponders for quantifying thermal biology and torpor in small mammals. J Therm Biol. 2012;37(4):250-4. doi:10.1016/j.jtherbio.2011.11.007.

19. Langer F, Fietz J. Ways to measure body temperature in the field. J Therm Biol. 2014;42:46-51. doi:10.1016/j.jtherbio.2014.03.002.

20. Nord A, Nilsson JF, Sandell MI, Nilsson J-Å. Patterns and dynamics of rest-phase hypothermia in wild and captive blue tits during winter. J Comp Physiol B. 2009;179(6):737-45. doi:10.1007/s00360-009-0357-1.

21. Nord A, Nilsson JF, Nilsson J-Å. Nocturnal body temperature in wintering blue tits is affected by roost-site temperature and body reserves. Oecologia. 2011;167(1):21-5.

22. vdB Morkel P, Miller M, Jago M, Radcliffe RW, du Preez P, Olea-Popelka $F$, et al. Serial temperature monitoring and comparison of rectal and muscle temperatures in immobilized free-ranging black rhinoceros (Diceros bicornis). J Zoo Wildl Med. 2012;43(1):120-4.

23. Haftorn S. Hypothermia of Tits in the Arctic Winter. Ornis Scand. 1972;3(2):153-66.

24. Moller AP. Body temperature and fever in a free-living bird. Comp Biochem Physiol B Biochem Mol Biol. 2010;156(1):68-74.

25. Pereyra ME, Morton ML. Nestling growth and thermoregulatory development in subalpine Dusky Flycatchers. Auk. 2001;118(1):116-36.

26. Nord A, Sköld-Chiriac S, Hasselquist D, Nilsson J-Å. A tradeoff between perceived predation risk and energy conservation revealed by an immune challenge experiment. Oikos. 2014;123(9):1091-100. doi:10.1111/oik.01221.

27. Piccione G, Caola G, Refinetti R. Maturation of the daily body temperature rhythm in sheep and horse. J Therm Biol. 2002;27(5):333-6. doi:10.1016/s0306-4565(01)00076-6.

28. Bouwknecht JA, Olivier B, Paylor RE. The stress-induced hyperthermia paradigm as a physiological animal model for anxiety: a review of pharmacological and genetic studies in the mouse. Neurosci Biobehav Rev. 2007;31(1):41-59. doi:10.1016/j.neubiorev.2006.02.002.

29. Busnardo C, Tavares RF, Resstel LBM, Elias LLK, Correa FMA. Paraventricular nucleus modulates autonomic and neuroendocrine responses to acute restraint stress in rats. Auton Neurosci Basic Clin. 2010;158(12):51-7. doi:10.1016/j.autneu.2010.06.003.

30. Blessing WW. Lower Brainstem pathways regulating sympathetically mediated changes in cutaneous blood flow. Cell Mol Neurobiol. 2003;23(4-5):527-38. doi:10.1023/a:1025020029037.

31. Adams NJ, Pinshow B, Gannes LZ, Biebach H. Body temperatures in free-flying pigeons. J Comp Physiol B Biochem Syst Environ Physiol. 1999;169(3):195-9. doi:10.1007/s003600050211. 
32. Gray DA, Maloney SK, Kamerman PR. Restraint increases afebrile body temperature but attenuates fever in Pekin ducks (Anas platyrhynchos). Am J Physiol Regul Integr Comp Physiol. 2008;294(5):R1666-71.

33. Hill RD, Schneider RC, Liggins GC, Schuette AH, Elliott RL, Guppy M, et al. Temperature during free diving of weddell seals. Am J Physiol. 1987;253(2):R344-51.

34. Ponganis PJ, Van Dam RP, Levenson DH, Knower T, Ponganis KV, Marshall $G$. Regional heterothermy and conservation of core temperature in emperor penguins diving under sea ice. Comp Biochem Physiol A Mol Integr Physiol. 2003;135(3):477-87. doi:10.1016/s1095-6433(03)00133-8.

35. Meir JU, Ponganis PJ. Blood temperature profiles of diving elephant seals. Physiol Biochem Zool. 2010;83(3):531-40. doi:10.1086/651070.

36. Benedict FG. The physiology of the elephant. Washington: Carnegie Institution; 1936.

37. Jensen SA, Mundry R, Nunn CL, Boesch C, Leendertz FH. Non-invasive body temperature measurement of wild chimpanzees using fecal temperature decline. J Wildl Dis. 2009;45(2):542-6.

38. Acquarone M, Born EW, Griffiths D, Knutsen L $\varnothing$, Wiig $\varnothing$, Gjertz I. Evaluation of etorphine reversed by diprenorphine for the immobilisation of free-ranging Atlantic walrus (Odobenus rosmarus rosmarus L.), vol. 9. NAMMCO Scientific Publications; 2015. doi:10.7557/3.2944.

39. Lubbe A, Hetem RS, McFarland R, Barrett L, Henzi PS, Mitchell D, et al Thermoregulatory plasticity in free-ranging vervet monkeys, Chlorocebus pygerythrus. J Comp Physiol B Biochem Syst Environ Physiol. 2014;184(6):799-809. doi:10.1007/s00360-014-0835-y.

40. Friebe A, Evans AL, Arnemo JM, Blanc S, Brunberg S, Fleissner G, et al. Factors affecting date of implantation, parturition, and den entry estimated from activity and body temperature in free-ranging brown bears. PLoS One. 2014;9(7). doi:10.1371/journal.pone.0101410.

41. Green JA, Tanton JL, Woakes AJ, Boyd IL, Butler PJ. Effects of long-term implanted data loggers on macaroni penguins Eudyptes chrysolophus. J Avian Biol. 2004;35(4):370-6. doi:10.1111/j.0908-8857.2004.03281.x.

42. Eichhorn G, Groscolas R, Le Glaunec G, Parisel C, Arnold L, Medina P, et al. Heterothermy in growing king penguins. Nat Commun. 2011;2. doi:10.1038/ncomms1436.

43. Bevan RM, Boyd IL, Butler PJ, Reid K, Woakes AJ, Croxall JP. Heart rates and abdominal temperatures of free-ranging South Georgian shags, Phalacrocorax georgianus. J Exp Biol. 1997;200(4):661-75.

44. Butler PJ, Bevan RM, Woakes AJ, Croxall JP, Boyd IL. The use of data loggers to determine the energetics and physiology of aquatic birds and mammals. Br J Med Biol Res. 1995;28:1307-17.

45. Tøien O, Blake J, Edgar DM, Grahn DA, Heller HC, Barnes BM. Hibernation in black bears: independence of metabolic suppression from body temperature. Science. 2011;331(6019):906-9. doi:10.1126/ science.1199435.

46. Long RA, Hut RA, Barnes BM. Simultaneous collection of body temperature and activity data in burrowing mammals: a new technique. J Wildl Manag. 2007;71(4):1375-9. doi:10.2193/2006-399.

47. Hilmer S, Algar D, Neck D, Schleucher E. Remote sensing of physiological data: impact of long term captivity on body temperature variation of the feral cat (Felis catus) in Australia, recorded via Thermochron iButtons. J Therm Biol. 2010;35(5):205-10. doi:10.1016/j. jtherbio.2010.05.002.

48. Mustonen A-M, Asikainen J, Kauhala K, Paakkonen T, Nieminen P. Seasonal rhythms of body temperature in the free-ranging raccoon dog (Nyctereutes procyonoides) with special emphasis on winter sleep. Chronobiol Int. 2007;24(6):1095-107. doi:10.1080/07420520701797999.

49. Dausmann KH. Measuring body temperature in the field-evaluation of external vs. implanted transmitters in a small mammal. J Therm Biol. 2005;30(3):195-202. doi:10.1016/j.jtherbio.2004.11.003.

50. Cooper CE, Withers PC. Patterns of body temperature variation and torpor in the numbat, Myrmecobius fasciatus (Marsupialia: Myrmecobiidae). J Therm Biol. 2004;29(6):277-84. doi:10.1016/j.jtherbio.2004.05.003.

51. Schmidt A, Alard F, Handrich Y. Changes in body temperatures in king penguins at sea: the result of fine adjustments in peripheral heat loss? Am J Physiol Regul Integr Comp Physiol. 2006;291(3):R608-18. doi:10.1152/ajpregu.00826.2005.

52. Niizuma Y, Gabrielsen GW, Sato K, Watanuki Y, Naito Y. Brunnich's guillemots (Uria lomvia) maintain high temperature in the body core during dives. Comp Biochem Physiol A Mol Integr Physiol. 2007;147(2):438-44 doi:10.1016/j.cbpa.2007.01.014.
53. Gilbert C, Le Maho Y, Perret M, Ancel A. Body temperature changes induced by huddling in breeding male emperor penguins. Am J Physiol Regul Integr Comp Physiol. 2007;292(1):R176-85. doi:10.1152/ ajpregu.00912.2005.

54. Nicol S, Andersen NA. Body temperature as an indicator of egg-laying in the echidna, Tachyglossus aculeatus. J Therm Biol. 2006;31(6):483-90. doi:10.1016/j.jtherbio.2006.05.001.

55. Warnecke L, Withers PC, Schleucher E, Maloney SK. Body temperature variation of free-ranging and captive southern brown bandicoots /soodon obesulus (Marsupialia: Peramelidae). J Therm Biol. 2007;32(2):72-7. doi:10.1016/j.jtherbio.2006.10.003.

56. Signer C, RufT, Schober F, Fluch G, Paumann T, Arnold W. A versatile telemetry system for continuous measurement of heart rate, body temperature and locomotor activity in free-ranging ruminants. Methods Ecol Evol. 2010;1(1):75-85. doi:10.1111/j.2041-210X.2009.00010.x.

57. Horning M, Haulena M, Tuomi PA, Mellish J-AE. Intraperitoneal implantation of life-long telemetry transmitters in otariids. BMC Vet Res. 2008;4. doi:10.1186/1746-6148-4-51.

58. Adelman JS, Córdoba-Córdoba S, Spoelstra K, Wikelski M, Hau M. Radiotelemetry reveals variation in fever and sickness behaviours with latitude in a free-living passerine. Funct Ecol. 2010;24(4):813-23. doi:10.1111/j.1365-2435.2010.01702.x.

59. Kruuk H, Taylor PT, Mom GAT. Body temperature and foraging behaviour of the Eurasian otter (Lutra lutra), in relation to water temperature. J Zool. 1997;241:689-97.

60. Brain C, Mitchell D. Body temperature changes in free-ranging baboons (Papio hamadryas ursinus) in the Namib Desert, Namibia. Int J Primatol. 1999;20(4):585-98. doi:10.1023/a:1020394824547.

61. Criscuolo F, Gauthier-Clerc M, Le Maho Y, Gabrielsen GW. Brood patch temperature during provocation of incubating common eiders in Ny-Alesund, Svalbard. Polar Res. 2001;20(1):115-8. doi:10.1111/j.1751-8369.2001.tb00044.x.

62. Schmutz JA. Survival of adult red-throated loons (Gavia stellate) may be linked to marine conditions. Waterbirds. 2014;37:118-24.

63. Thouzeau C, Peters G, Le Bohec C, Le Maho Y. Adjustments of gastric $\mathrm{pH}$, motility and temperature during long-term preservation of stomach contents in free-ranging incubating king penguins. J Exp Biol. 2004;207(15):2715-24. doi:10.1242/jeb.01074.

64. Weissenboeck NM, Schober F, Fluch G, Weiss C, Paumann T, Schwarz C, et al. Reusable biotelemetric capsules: a convenient and reliable method for measuring core body temperature in large mammals during gut passage. J Therm Biol. 2010;35(3):147-53. doi:10.1016/j. jtherbio.2010.02.001.

65. Wilson RP, Putz K, Gremillet D, Culik BM, Kierspel M, Regel J, et al. Reliability of stomach temperature-changes in determining feeding characteristics of seabirds. J Exp Biol. 1995;198(5):1115-35.

66. Kato A, Naito Y, Watanuki Y, Shaughnessy PD. Diving pattern and stomach temperatures of foraging king cormorants at subantarctic Macquarie Island. Condor. 1996:98(4):844-8. doi:10.2307/1369867.

67. Kuhn CE, Costa DP. Identifying and quantifying prey consumption using stomach temperature change in pinnipeds. J Exp Biol. 2006;209(22):4524-32. doi:10.1242/jeb.02530.

68. Hedd A, Gales R, Renouf D. Can stomach temperature telemetry be used to quantify prey consumption by seals? A re-examination. Polar Biol. 1996;16(4):261-70. doi:10.1007/s003000050053.

69. Wilson RP, Kierspel MAM. A method for retrieval of anchored stomach probes from seabirds. Mar Ecol Prog Ser. 1998;163:295-7. doi:10.3354/ meps163295.

70. Heide-Jorgensen M, Nielsen N, Hansen R, Blackwell S. Stomach temperature of narwhals (Monodon monoceros) during feeding events. Anim Biotelem. 2014;2(1):9.

71. Handrich Y, Bevan RM, Charrassin JB, Butler PJ, Putz K, Woakes AJ, et al. Hypothermia in foraging king penguins. Nature. 1997;388(6637):64-7. doi:10.1038/40392.

72. Enstipp MR, Gremillet D, Jones DR. Heat increment of feeding in double-crested cormorants (Phalacrocorax auritus) and its potential for thermal substitution. J Exp Biol. 2008;211(1):49-57. doi:10.1242/ jeb.012229.

73. Schreer JF, Lapierre JL, Hammill MO. Stomach temperature telemetry reveals that harbor seal (Phoca vitulina) pups primarily nurse in the water. Aquat Mamm. 2010;36(3):270-7. doi:10.1578/am.36.3.2010.270. 
74. Sauve CC, Van de Walle J, Hammill MO, Arnould JPY, Beauplet G. Stomach temperature records reveal nursing behaviour and transition to solid food consumption in an unweaned mammal, the harbour seal pup (Phoca vitulina). PLoS one. 2014;9(2). doi:10.1371/journal. pone.0090329.

75. Reuter RR, Carroll JA, Hulbert LE, Dailey JW, Galyean ML. Technical note: development of a self-contained, indwelling rectal temperature probe for cattle research. J Anim Sci. 2010;88(10):3291-5. doi:10.2527/ jas.2010-3093.

76. Burdick NC, Carroll JA, Dailey JW, Randel RD, Falkenberg SM, Schmidt TB. Development of a self-contained, indwelling vaginal temperature probe for use in cattle research. J Therm Biol. 2012;37(4):339-43. doi:10.1016/j.jtherbio.2011.10.007.

77. Munn AJ, Barboza PS, Dehn J. Sensible heat loss from muskoxen (Ovibos moschatus) feeding in winter: small calves are not at a thermal disadvantage compared with adult cows. Physiol Biochem Zool. 2009;82(5):455-67. doi:10.1086/605400.

78. Audet $D$, Thomas DW. Evaluation of the accuracy of body temperature measurement using external radio transmitters. Can J Zool. 1996;74(9):1778-81. doi:10.1139/z96-196.

79. Nord A, Chiriac S, Hasselquist D, Nilsson J-Å. Endotoxin injection attenuates rest-phase hypothermia in wintering great tits through the onset of fever. Funct Ecol. 2013;27(1):236-44. doi:10.1111/1365-2435.12003

80. Scholander PF, Hock R, Walters V, Johnson F, Irving L. Heat regulation in some arctic and tropical mammals and birds. Biol Bull. 1950;99(2):237-58.

81. Larcombe A. Measurement of southern brown bandicoot (Isoodon obesulus) body temperature using internal and external telemeters. J R Soc West Aust. 2007;Part 90(3):161-3.

82. Bonter DN, Bridge ES. Applications of radio frequency identification (RFID) in ornithological research: a review. J Field Ornithol. 2011;82(1):110. doi:10.1111/j.1557-9263.2010.00302.x.

83. Barclay RMR, Calcounis MC, Crampton LH, Stefan C, Vonhof MJ, Wilkinson $\mathrm{L}$, et al. Can external radiotransmitters be used to assess body temperature and torpor in bats? J Mammal. 1996;77:1 102-6.

84. Bakken GS, Reynolds PS, Kenow KP, Korschgen CE, Boysen AF. Thermoregulatory effects of radiotelemetry transmitters on mallard ducklings. J Wildl Manag. 1996;60(3):669-78.

85. Vuarin P, Dammhahn M, Henry P-Y. Individual flexibility in energy saving: body size and condition constrain torpor use. Funct Ecol. 2013;27(3):793-9. doi:10.1111/1365-2435.12069.

86. Boyd IL. Skin temperatures during free-ranging swimming and diving in antarctic fur seals. J Exp Biol. 2000;203:1907-14.

87. Willis CKR, Brigham RM. Defining torpor in free-ranging bats: experimental evaluation of external temperature-sensitive radiotransmitters and the concept of active temperature. J Comp Physiol B Biochem Syst Environ Physiol. 2003;173(5):379-89.

88. Murray DL, Fuller MR. A critical review of the effects of marking on the biology of vertebrates. Research techniques in animal ecology: controversies and consequences; 2000

89. Kenward RE. A manual for wildlife radio tagging. London: Academic Press; 2001.

90. Wilson RP, McMahon CR. Measuring devices on wild animals: what constitutes acceptable practice? Front Ecol Environ. 2006;4(3):147-54. doi:10.1890/1540-9295(2006)004[0147:mdowaw]2.0.co;2.

91. McCafferty DJ, Moncrieff JB, Taylor IR, Boddie GF. The use of IR thermography to measure the radiative temperature and heat loss of a barn owl (Tyto alba). J Therm Biol. 1998;23(5):311-8.

92. Weissenboeck NM, Weiss CM, Schwammer HM, Kratochvil H. Thermal windows on the body surface of African elephants (Loxodonta africana) studied by infrared thermography. J Therm Biol. 2010;35(4):182-8. doi:10.1016/j.jtherbio.2010.03.002.

93. Amiel JJ, Chua B, Wassersug RJ, Jones DR. Temperature-dependent regulation of blood distribution in snakes. J Exp Biol. 2011;214(9):1458-62.
94. Bakken GS, Van Sant MJ, Lynott AJ, Banta MR. Predicting small endotherm body temperatures from scalp temperatures. J Therm Biol. 2005;30(3):221-8.

95. Giloh M, Shinder D, Yahav S. Skin surface temperature of broiler chickens is correlated to body core temperature and is indicative of their thermoregulatory status. Poult Sci. 2012;91(1):175-88. doi:10.3382/ ps.2011-01497.

96. Teunissen LPJ, Daanen HAM. Infrared thermal imaging of the inner canthus of the eye as an estimator of body core temperature. J Med Eng Technol. 2011;35(3-4):134-8. doi:10.3109/03091902.2011.554595.

97. Stewart M, Webster J, Verkerk G, Schaefer A, Colyn J, Stafford K. Non-invasive measurement of stress in dairy cows using infrared thermography. Physiol Behav. 2007;92(3):520-5. doi:10.1016/j. physbeh.2007.04.034.

98. Edgar JL, Lowe JC, Paul ES, Nicol CJ. Avian maternal response to chick distress. Proc R Soc B Biol Sci. 2011;278(1721):3129-34. doi:10.1098/ rspb.2010.2701.

99. McCafferty DJ, Moss S, Bennett K, Pomeroy PP. Factors influencing the radiative surface temperature of grey seal (Halichoerus grypus) pups during early and late lactation. J Comp Physiol B Biochem Syst Environ Physiol. 2005;175((6):423-31. doi:10.1007/s00360-005-0004-4.

100. Rowley JJL, Alford RA. Non-contact infrared thermometers can accurately measure amphibian body temperatures. Herpetol Rev. 2007;38(3):308-11.

101. Carretero MA. Measuring body temperatures in small lacertids: infrared vs. contact thermometers. Basic Appl Herpetol. 2012;26:99-105.

102. Warnecke L. Quantifying torpor in small mammals non-invasively using infrared thermocouples. J Therm Biol. 2012;37(5):380-3. doi:10.1016/j. jtherbio.2012.02.002

103. Davidson AJ, Aujard F, London B, Menaker M, Block GD. Thermochron iButtons: an inexpensive method for long-term recording of core body temperature in untethered animals. J Biol Rhythms. 2003;18(5):430-2. doi:10.1177/0748730403256066.

104. Roznik EA, Alford RA. Does waterproofing Thermochron iButton dataloggers influence temperature readings? J Therm Biol. 2012;37(4):2604. doi:10.1016/j.jtherbio.2012.02.004.

105. Williams JB, Tieleman BI, Shobrak M. Validation of temperature-sensitive radio transmitters for measurement of body temperature in small animals. Ardea. 2009;97(1):120-4.

106. Scholander PF, Hock R, Walters V, Irving L. Adaptation to cold in Arctic and tropical mammals and birds in relation to body temperature, insulation, and basal metabolic rate. Biol Bull. 1950;99(2):259-71.

107. Brigham RM. Daily torpor in a free-ranging goatsucker, the common poorwill (Phalaenoptilus nuttallii). Physiol Zool. 1992;65(2):457-72. doi:10.2307/30158263.

108. Niedermann R, Wyss E, Annaheim S, Psikuta A, Davey S, Rossi RM. Prediction of human core body temperature using non-invasive measurement methods. Int J Biometeorol. 2014;58(1):7-15. doi:10.1007/ s00484-013-0687-2.

109. Taylor EN, DeNardo DF, Malawy MA. A comparison between pointand semi-continuous sampling for assessing body temperature in a free-ranging ectotherm. J Therm Biol. 2004;29(2):91-6. doi:10.1016/j. jtherbio.2003.11.003.

110. Al-Khalidi FQ, Saatchi R, Burke D, Elphick H, Tan S. Respiration rate monitoring methods: a review. Pediatr Pulmonol. 2011;46(6):523-9. doi:10.1002/ppul.21416.

111. Betke M, Hirsh DE, Makris NC, McCracken GF, Procopio M, Hristov NI, et al. Thermal imaging reveals significantly smaller Brazilian free-tailed bat colonies than previously estimated. J Mammal. 2008;89(1):18-24. doi:10.1644/07-mamm-a-011.1.

112. Cooke SJ, Midwood JD, Thiem JD, Klimley P, Lucas MC, Thorstad EB, et al. Tracking animals in freshwater with electronic tags: past, present and future. Anim Biotelem. 2013;1(5)

113. Nikita KS. Handbook of medical telemetry. Hoboken: Wiley; 2014. doi:10.1002/9781118893715. 